\title{
- Governança digital e transparência pública: avanços, desafios e oportunidades
}

\author{
Digital governance and public transparency: advances, challenges \\ and opportunities
}

Caroline Stéphanie Francis dos Santos Maciela,*

\begin{abstract}
RESUMO: Experimenta-se hoje um cenário de grave emergência de saúde pública que abalou as estruturas econômicas e administrativas do Estado brasileiro e dos demais países no mundo. Nesse contexto, tem se discutido como manter a máquina administrativa em funcionamento nos pilares do trabalho remoto e da digitalização da prestação de serviços públicos e das funções administrativas. Apesar dos danos sociais que serão sentidos pelos próximos anos, o momento configura como propício para impulsionar a implementação de uma governança digital no Brasil, que promova maior transparência pública, produtividade administrativa e participação social, por meio de mecanismos de tecnologia da informação e da comunicação. Diante disso, este artigo almeja refletir sobre esses pontos, sustentando-se em três questões fundamentais: a) quais são os avanços já promovidos no país em acesso à informação, transparência e participação, relacionados à governança digital?; b) que desafios e obstáculos permanecem e dificultam uma revolução tecnológica mais profunda na administração pública federal?; c) como o atual panorama pode contribuir para acelerar esse processo? Busca-se contribuir para se alcançar tais respostas, dentro de uma linha de pesquisa teórica-normativa (de natureza qualitativa) e a partir do procedimento metodológico de análise de conteúdo (levantamento de dados primários e secundários).
\end{abstract}

Palavras-chave: Governança Digital; Tecnologia da Informação e Comunicação; Transparência Pública; Participação Social; Pandemia.

ABSTRACT: Today, a scenario of serious public health emergency is being experienced that has shaken the economic and administrative structures of the Brazilian State and of other countries in the world. In this context, it has been discussed how to keep the public machine running on the pillars of remote work and the digitization of public services and administrative functions. Despite the social damage that will be felt over the next years, the moment appears to be favorable to boost the implementation of digital governance in Brazil, which could promote greater public transparency, administrative productivity and social participation, through mechanisms of information and communication technology. Therefore, this paper aims to reflect on these points, based on three fundamental questions: a) what are the advances already promoted in the country on access to information, transparency and participation, related to digital governance?; b) what challenges and obstacles remain and inhibit a deeper technological revolution in brazilian public administration?; c) how can the current scenario contribute to accelerate this process? We seek to contribute to achieving such answers, based on a theoretical and legal line of research (qualitative nature) and the content analysis methodological procedure (gathering primary and secondary data).

Keywords: Digital Governance; Information and Communication Technology; Public Transparency; Social Participation; Pandemic.

\footnotetext{
a Programa de Pós-Graduação em Direito, Universidade Federal de Minas Gerais, Belo Horizonte, MG, Brasil.

* Correspondência para/Correspondence to: Caroline Stéphanie Francis dos Santos Maciel. E-mail: csfmaciel@gmail.com.
}

Recebido em/Received: 22/05/2020; Aprovado em/Approved: 22/09/2020.

Artigo publicado em acesso aberto sob licença CC BY 4.0 Internacional @)(P) 


\section{INTRODUÇÃO}

A Constituição de 1988 (CF/88) trouxe a base normativa para a difusão do uso de mecanismos de participação popular e para a construção de uma cultura da transparência do Poder público (Brasil, 1988). A partir dessas premissas, passou-se a buscar a consolidação de uma sociedade da informação no Brasil, cada vez mais profundamente influenciada pelo uso de ferramentas e recursos tecnológicos.

Com isso, foram construídas leis e políticas públicas nos pilares da transparência dos gastos públicos, do acesso à informação e de governo aberto e eletrônico. Alguns dos marcos mais relevantes no tema foram: a Lei de Responsabilidade Fiscal (LRF) - Lei Complementar $n^{\circ} 101,2000$, que tratou da transparência e responsabilidade na gestão fiscal (Brasil, 2000); foi seguida, alguns anos depois, pela criação do "Portal da Transparência" do governo federal (Brasil, 2004); e a Lei de Acesso à Informação (LAI) - Lei ${ }^{\circ} 12.527$ (Brasil, 2011), que, no âmago do Executivo Federal, foi regulamentada pelo Decreto 7.724 (Brasil, 2012) e veio para prever as regras e procedimentos para 0 exercício do direito de acesso à informação pública.

Mais recentemente, com o Decreto $n^{\circ} 8.777$ (Brasil, 2016a), foi instituída a política de dados abertos do governo federal e foi criado o Código de Defesa do Usuário de Serviços Públicos (CDU) através da Lei n 13.460 (Brasil, 2017a) e do Decreto $n^{\circ} 9.094$ (Brasil, 2017b), na busca pela proteção dos seus direitos e de simplificação do atendimento público.

Especificamente quanto à transformação digital do setor público, foi criada a Plataforma Cidadania Digital, pelo Decreto n 8.936 (Brasil, 2016b), com o objetivo de ofertar serviços públicos digitais; a Política de Governança Digital (Decreto n 8.638 Brasil, 2016c), que buscava propagar o uso da tecnologia da informação na prestação de serviços públicos e estimulava a participação e monitoramento desses serviços pelos cidadãos (e foi recentemente revogada pelo Decreto $n^{\circ} 10.332 / 2020$ ); o Sistema Nacional de Transformação Digital (Decreto $n^{\circ}$ 9.319 - Brasil, 2018), com a finalidade de harmonizar as iniciativas do Executivo federal no ambiente digital; por fim, a recente Estratégia de Governo Digital, que, através do Decreto $n^{\circ} 10.332$, traz os princípios, objetivos e iniciativas a nortearem a transformação digital do governo federal (Brasil, 2020a).

Mais de 30 anos depois da nova ordem constitucional, a implementação de uma governança digital, informacional e participativa ${ }^{1}$ no Brasil continua sendo um desafio, sobretudo devido a barreiras burocráticas, obstáculos ainda existentes na abertura dos dados governamentais e a falta de inteligibilidade da informação e da linguagem jurídica.

Apesar de ser inegável o grande progresso na área, o país tem caminhado lentamente e, muitas vezes, inconstante e descontinuamente no processo de revolução digital do

\footnotetext{
10 uso do termo governança é utilizado neste artigo para abarcar, em um só conceito, a ideia de um esforço contínuo em prol da efetividade e sucesso das políticas públicas digitais, informacionais e participativas. Nesse sentido, a expressão governança digital envolveria o grau de efetividade da digitalização das atividades públicas, em conformidade com mais novos padrões tecnológicos e inovações. Por sua vez, a governança informacional traz uma análise da efetividade do acesso à informação, que depende do grau, contexto, finalidades e impactos das políticas de transparência pública. Assim, implementar uma governança informacional no país é buscar o efetivo acesso à informação, de modo transparente, que promova outros direitos fundamentais e gere ganhos na qualidade da gestão pública, através da melhoria dos serviços públicos prestados e do processo decisório. Da mesma forma, o conceito se aplica para a efetivação de um modelo mais participativo e democrático no país, de maior horizontalização dos processos decisórios e ampliação do leque de atores envolvidos. Esses três aspectos (digital, informacional e participativo) estão intimamente conectados e devem ser somados, no entendimento ora adotado, para uma boa governança pública.
} 
setor público, apto a promover maior transparência e participação. Todavia, com a recente pandemia do coronavírus demostrou-se a necessidade urgente de virtualização das atividades estatais. Seus impactos serão sentidos por muitos anos e é possível dizer que promoverá novas tendências na Administração Pública e mudanças institucionais profundas, acelerando o seu processo de digitalização.

Diante do exposto, este artigo busca compreender o histórico de evolução da governança digital no país enquanto meio capaz de promover a transparência pública e participação social, a partir da análise das políticas públicas instituídas ao longo dos anos e das normas vigentes no tema. Ademais, pretende decifrar os desafios que ainda persistem e freiam a propagação do uso de recursos tecnológicos na Administração Pública federal, bem como os limites jurídicos à virtualização dos processos decisórios e as novas oportunidades de maior transparência e participação virtuais geradas pelo recente contexto de isolamento social e trabalho remoto, decorrentes da pandemia do coronavírus. Para tanto, adota a estratégia qualitativa de pesquisa teóricanormativa e utiliza o procedimento metodológico de análise de conteúdo para a compreensão das normas em transparência e participação e suas conexões contextuais. Com isso, busca atribuir sentido ao material levantado, em especial dados primários sobre o histórico de marcos legais e normativos e dados secundários (levantamento bibliográfico).

\section{A EVOLUÇÃO DA GOVERNANÇA DIGITAL NO BRASIL: EM QUE JÁ AVANÇAMOS?}

As raízes da implementação de uma governança digital no Brasil remontam a instauração de um novo cenário institucional pela Constituição de 1988 (Brasil, 1988) e a construção de normas e políticas públicas desde 1988 até atualmente, primeiramente voltadas à transparência pública e participação social e, posteriormente, relacionadas ao uso do ambiente virtual na gestão pública.

Nesse sentido, a $\mathrm{CF} / 88$ prevê o direito de acesso à informação no seu art. $5^{\circ}$, XIV e XXXIII, associando-o aos princípios que devem reger a administração pública, como o da publicidade (art. $5^{\circ}$, LX e art. 37), impessoalidade (art. 37, $\$ 1^{\circ}$ ) e moralidade (art. $5^{\circ}$, LXXIII), bem como à liberdade de expressão e de imprensa (art. 220) - (Brasil, 1988).

A aproximação entre o princípio da publicidade e o da transparência se dá na medida em que o dever de publicidade dos atos administrativos e de divulgação das informações públicas deve ser cumprido de modo efetivamente transparente e acessível para os cidadãos (Bandeira de Mello, 2013). Não basta apenas publicar formalmente os dados oficiais sem que se forneça os instrumentos necessários para torná-lo inteligível para a sociedade civil, o que envolve questões como a sua divulgação em formato aberto, em linguagem cidadã e a facilidade no seu acesso e compreensão. Todavia, nem sempre essas discussões aparecem quando se fala em transparência pública, conforme demonstra Frederick Shauer (2014, p. 87):

Una concepción positiva de la transparencia podría apoyar los esfuerzos tendientes a hacer que la información sea además fácilmente utilizable y no simplemente disponible. Tal es la diferencia, por ejemplo, entre una obligación de publicación de información y una solicitud de acceso. Sin embargo, la mayoría de 
las concepciones actuales sobre transparencia atienden más a la disponibilidad que a la accesibilidad de la información ${ }^{2}$.

Ademais, a transparência é uma condição para se garantir a observância da impessoalidade e da moralidade na gestão da coisa pública, já que permite o controle dos atos administrativos. Nesse sentido, a partir do texto constitucional, busca-se tornar a administração pública mais transparente e eficiente, desenvolvendo-se novos mecanismos de responsabilização dos agentes públicos (Oliveira; Bodart, 2015).

O primeiro marco legal pós-CF/88 de grande impacto 3 na transparência e accountability públicas foi a Lei de Responsabilidade Fiscal (LRF). A LRF instituiu a transparência na gestão fiscal, que garanta o acesso dos cidadãos a informações referentes às atividades financeiras do Estado e explicitou os procedimentos a serem observados na prestação das contas públicas e na ampla divulgação desses dados (Cruz et al., 2001), inclusive através de meios eletrônicos de acesso público (art. 48 da LRF) - (Brasil, 2000).

Para Pinho e Sacramento (2009, p. 1359), a LRF:

[...] impôs limites e condições para a gestão das receitas, despesas e quanto ao endividamento; exigiu transparência das contas públicas e o planejamento como rotina na administração fiscal, bem como a responsabilização pelo seu descumprimento.

A partir disso, incentivou a participação social na formulação dos orçamentos públicos (art. $48, \delta 1^{\circ}$ ); estabeleceu a fiscalização através de sistemas de controle interno e externo (art. 59), além do controle social, e, ainda, determinou a responsabilização de agentes e gestores públicos. No seu texto, já há algumas referências ao uso de ambientes virtuais e meios eletrônicos como instrumentos para prestar contas públicas, garantir o acesso à informação e a controle social (Brasil, 2000).

No que tange ao exercício das funções administrativas de controle, correção, prevenção e ouvidoria (Oliveira; Bodart, 2015), após a LRF, em 2003, foi criada a Controladoria Geral da União (CGU), para supervisionar o sistema de controle interno do Executivo federal e incrementar a transparência na gestão pública (Brasil, 2003).

Em sequência, o governo federal lançou o "Portal da Transparência", que permite o acompanhamento e fiscalização do uso do dinheiro público; dentre suas funções, detalha a execução das despesas públicas e o resultado de licitações e compras governamentais (Brasil, 2004). Apesar do grande impacto e valor da ferramenta, ao longo dos anos, foi constantemente colocada de lado, ao não ter sido foco de priorização política que garantisse a atualidade dos seus dados, o seu aperfeiçoamento tecnológico e melhorias na usabilidade. Nesse sentido, apresentou problemas como a ausência de atualizações periódicas dos dados, gerando zonas de opacidade informacional, e deficiências de usabilidade e navegabilidade dos usuários (Resende; Nassif, 2015). Em 2018, o portal foi aprimorado justamente para facilitar o seu uso e melhorar sua apresentação e utilização pelos cidadãos. Continua, no entanto, sendo um instrumento pouco atraente para os cidadãos como um todo e seu uso ainda não

\footnotetext{
2 Tradução livre da autora: “Uma concepção positiva de transparência poderia apoiar os esforços para tornar as informações facilmente utilizáveis e não simplesmente disponíveis. Essa é a diferença, por exemplo, entre a obrigação de publicar informações e uma solicitação de acesso. No entanto, a maioria das concepções atuais de transparência se concentra mais na disponibilidade do que na acessibilidade das informações."

${ }^{3}$ A linha do tempo que orienta a ordem desses marcos legais utilizada neste artigo é apresentada pela Controladoria Geral da União (CGU) em seu site (Brasil, 2020b).
} 
é amplamente difundido, senão por entidades especializadas, organizações da sociedade civil e outros organismos e experts que atuam na área.

O grande marco da transparência pública foi a promulgação da Lei $n^{\circ}$ 12.527/2011 denominada de Lei de Acesso à Informação (LAI), que veio para regulamentar o direito constitucional dos cidadãos de acesso à informação. Aplica-se a todos os entes federados e aos três poderes e estabelece parâmetros para a expansão da transparência pública ativa e procedimentos e prazos para que a Administração Pública responda às solicitações de acesso à informação - transparência passiva (Brasil, 2011). Desse modo, busca vencer a cultura do sigilo enraizada na gestão pública brasileira e estabelecer em seu lugar uma política de acesso. Também tem como objetivo tornar a disponibilização ativa das informações públicas a regra, fixando o entendimento de que a informação pertence ao cidadão (Merlo; Bassi; Cruz, 2014).

Nesse sentido, com a LAI (2011), veio a obrigatoriedade legal de divulgação eletrônica dos dados governamentais através de sua disponibilização nos sites oficiais dos governos subnacionais, salvo nos municípios com menos de dez mil habitantes (art. $8^{\circ}$, $\S 2^{\circ}$ e $\$ 4^{\circ}$ ). Trouxe uma série de componentes obrigatórios desses sites (Soares; Jardim; Hermont, 2013), tais como:

a) Conter ferramenta de pesquisa de conteúdo;

b) Gerar relatórios em diversos formatos e padrões abertos;

c) Possibilitar o acesso automatizado aos dados, aptos a serem lidos por máquinas;

d) Atualizar periodicamente as informações;

e) Garantir acessibilidade de pessoas com deficiência;

Todavia, ao menos inicialmente, não houve uma preocupação com a articulação interfederativa dos dados e nem com a sistematização de um padrão único de portal entre os entes e os três poderes (apenas entre os órgãos e entidades do Executivo federal). Como resultado, não havia homogeneidade na criação das páginas pelos governos subnacionais, o que foi resolvido parcialmente com o lançamento de um conjunto de recomendações da $\mathrm{CGU}^{4}$ (Resende; Nassif, 2015). Apesar disso, o fato de não haver um portal único para todos os poderes e entes federados, centralizando os dados públicos como um todo, e a partir do qual as páginas específicas de cada uma dessas esferas seja derivada de um ponto central, contribui para dificultar o interesse, acesso e utilização das informações pelos cidadãos.

O Decreto $n^{\circ} 7.724 / 2012$ é o ato normativo regulamentador da LAI no Poder Executivo federal. Trouxe algumas obrigações legais para o governo federal no que tange à transparência ativa, tal qual a divulgação no site oficial das respostas aos pedidos de acesso mais frequentes da sociedade (art. $7^{\circ}, \S 2^{\circ}$, VII). Detalhou também com maior profundidade o procedimento de acesso à informação (transparência passiva), em especial o direito de recurso em caso de negativa (arts. 21 a 24) - (Brasil, 2012).

Outro ato normativo secundário que merece destaque na pauta da transparência é o Decreto $n^{\circ} 8.777 / 2016$, que instituiu a política de dados abertos do Executivo federal. Seu principal objetivo é fomentar a disponibilização de dados governamentais acessíveis ao público, estruturados em formato aberto, de acesso e uso livre e capazes de serem automaticamente legíveis por máquinas (art. $2^{\circ}$, III c/c art. $1^{\circ}, \mathrm{I}$ ). Envolve, 
portanto, o desenvolvimento e utilização de novos recursos da tecnologia da informação para ampliar a transparência, participação e controle social (art. $1^{\circ}$, V e VIII) - (Brasil, 2016a).

Não há, porém, uma lei geral de dados abertos vigente no Brasil, que padronize as ferramentas de disponibilização de dados abertos nos entes estaduais e municipais e nos três poderes. Outra possibilidade seria a alteração e complementação da LAl, enquanto a lei que regulamenta o direito constitucional à informação, passando a trazer mais dispositivos específicos sobre o padrão aberto de dados públicos. Já tramitam alguns projetos de lei no Congresso Nacional com a finalidade de criar uma lei nesses moldes, como o Projeto de Lei (PL) nº 7.804 (Brasil, 2014).

Ainda em relação à abertura de dados governamentais, entre os anos de 2011 e 2018, foram apresentados quatro Planos de Ação Nacionais à Open Government Partnership (OGP), nos quais o Brasil assume uma série de compromissos para transformar a gestão pública e tornar o governo mais aberto e transparente. Dentre eles, vários se relacionam com a criação e aprimoramento de canais institucionais virtuais para articulação do governo com a sociedade civil e com o uso de softwares livres para facilitar a participação social, permitindo o envio de sugestões e reclamações em tempo real na formulação de políticas públicas.

Nesse sentido, segundo Freitas e Dacorso (2014, p. 880), o governo brasileiro se compromete a:

[...] se relacionar com a sociedade de novas maneiras e a disponibilizar conteúdos e formatos de informações que atendam a interesses de diferentes públicos. O governo brasileiro compromete-se também a implementar soluções de abertura de dados e promover o aumento da integridade das informações públicas, por meio de uma plataforma aberta. Assim, percebe-se que a tecnologia da informação desempenha um papel relevante no sentido de trazer a transparência e disponibilizar as informações públicas que a sociedade tanto requer (Torres, 2004).

Outro importante marco legal foi a criação do Código de Defesa do Usuário de Serviços Públicos (CDU) através da Lei $n^{\circ} 13.460 / 2017$, que veio para dar cumprimento ao caput e inciso I do art. $37, \S 3^{\circ}$ e ao art. 175 , § único II e IV da CF/88. Quanto ao direito à informação, o CDU trouxe, por exemplo, a necessidade de publicidade sobre os serviços públicos prestados e os respectivos órgãos responsáveis (art. $3^{\circ}$ ), de divulgação de uma carta de serviços pelos órgãos, para informar, direcionar e facilitar o acesso do cidadão aos serviços públicos (art. $7^{\circ}$ ), o direito a informações precisas e de fácil acesso, disponibilizadas na internet (art. $6^{\circ}, \mathrm{Vl}$ ) e o uso de soluções tecnológicas na simplificação do atendimento e no compartilhamento de informações públicas (art. $5^{\circ}$, XIII). Quanto à participação dos cidadãos, criou o conselho de usuários para assegurá-la na prestação e na avaliação dos serviços públicos, de natureza consultiva (art. 18) e dá um maior destaque ao papel das ouvidorias no monitoramento da qualidade do serviço público prestado (art. 13) - (Brasil, 2017a).

O CDU foi regulamentado, no âmbito federal, pelo Decreto $n^{\circ} 9.094 / 2017$, que busca dar efetividade à simplificação do atendimento ao cidadão e instituir a carta de serviços ao usuário, detalhando mais os procedimentos e exigências na sua elaboração pelos órgãos do Executivo federal (Brasil, 2017b).

Ainda que tenha um grande valor, o conteúdo da regulação foi bastante tímido, especialmente em razão da longa mora legislativa (Carvalho; Venturini, 2019) e já chega defasado, pois, enquanto as discussões hoje já giram em torno do uso de inteligência 
artificial no exercício das funções administrativas aptas a serem automatizadas por máquinas, a lei sequer aproveitou a oportunidade para aprofundar sobre a prestação eletrônica de serviços públicos. Há, ainda, preocupações quanto a efetividade dos mecanismos de participação trazidos, que dependem de uma mudança institucional mais profunda na administração pública para lhes dar concretude.

Especificamente quanto à transformação digital do setor público, foi criada a Plataforma Cidadania Digital, pelo Decreto $n^{\circ}$ 8.936/2016, com o objetivo de ofertar serviços públicos digitais em um canal único e integrado do governo federal (Brasil, 2016b). Os seus principais desafios são a efetiva integração de todos os órgãos e entidades nesse mesmo canal, a atratividade e fácil acessibilidade do portal pelo cidadão, de modo que a ferramenta seja amplamente utilizada e a digitalização integral dos serviços e não apenas uma parte deles ser iniciada ou acompanhada de modo digital, e, ainda, depender de atendimento presencial.

A Política de Governança Digital, criada pelo Decreto $n^{\circ} 8.638 / 2016$, buscava fixar as diretrizes para o uso de mecanismos de tecnologia da informação e comunicação nas relações do governo com a sociedade civil. O seu enfoque era, portanto, a operacionalização de estratégias digitais na busca pela expansão do acesso à informação, transparência e participação social (Brasil, 2016c). Todavia, ela foi recentemente revogada pelo Decreto $\mathrm{n}^{\circ}$ 10.322/2020, que trouxe uma nova estratégia digital para o governo federal (Brasil, 2020a).

Já o Decreto $n^{\circ}$ 9.319/2018 instituiu o Sistema Nacional de Transformação Digital, com a finalidade de harmonizar as iniciativas digitais do Executivo federal e estabeleceu a estrutura para a implantação da Estratégia Brasileira para a Transformação Digital (Brasil, 2018). É preciso, antes de mais nada, que sua implementação seja verdadeiramente focada nas necessidades dos cidadãos.

Mais recentemente, o Decreto $n^{\circ} 9.756 / 2019$ busca unificar os canais digitais do governo federal, facilitando o acesso dos cidadãos e reduzindo os custos de manutenção de tantos portais (Brasil, 2019).

Por fim, o Decreto $n^{\circ} 10.322 / 2020$ instituiu a Estratégia de Governo Digital para a administração pública federal, no período de 2020 a 2022. Nesse sentido, foram fixados uma série de objetivos e iniciativas a serem tomadas para a transformação digital do governo federal, dentro de prazos previamente estabelecidos. São 18 objetivos gerais, dentre os quais merecem destaque: i) o aumento da participação cidadã na elaboração de políticas públicas (objetivo 14), através, por exemplo, da disponibilização de nova plataforma de participação até 2021; ii) a reformulação dos canais de acesso (objetivo 13), como através da integração dos portais da transparência, de dados abertos e da ouvidoria ao portal único gov.br até 2020 e iii) a integração de serviços públicos, de dados e sistemas do governo federal (objetivo 6) (Brasil, 2020a).

Em linhas gerais, a estratégia digital parece focar em alguns dos problemas fulcrais que impedem a profunda transformação digital da administração pública, ao menos em nível federal. Todavia, ainda resta saber se os prazos serão cumpridos e as metas alcançadas, sem novas revogações e instabilidades na continuidade de políticas públicas no tema. Isso porque não faltam atos normativos secundários abordando a digitalização da administração pública federal e, muitas vezes, essas políticas são descontinuadas pelos governos seguintes, que preferem iniciar seus próprios programas do que aprimorar os já existentes.

Apesar dessa miríade de atos do Executivo, a efetividade da transformação digital governamental ainda não é uma realidade. Muito além da mera oferta de serviços públicos eletrônicos, o que, por si só, ainda é muito incipiente no país, a ideia de 
governança digital envolve o uso de sistemas tecnológicos para a gestão da informação e da comunicação governamentais, bem como "a participação do cidadão nos processos de tomada de decisão através de interações online" (Mezzomo; Wiedenhoft; Santos, 2018).

Significa, portanto, mudar a forma como se dão as relações e interações entre Estado e sociedade civil e se valer da tecnologia para ampliar o leque de stakeholders não estatais envolvidos na construção de políticas públicas, em um contexto de democracia digital. A virtualização e interatividade das interações digitais têm o potencial de ampliar a participação e controle sociais, reduzir os custos (financeiros, temporais e espaciais) na prestação de serviços públicos, aumentar sua efetividade e qualidade e aumentar a transparência pública. A implementação de uma governança digital configura, portanto, como uma boa estratégia regulatória e um mecanismo facilitador da democracia (Schauer, 2014).

\section{BARREIRAS CULTURAIS E ESTRUTURAIS À DIGITALIZAÇÃO DA MÁQUINA PÚBLICA: O QUE IMPEDE DE PROGREDIR AINDA MAIS?}

Apesar dos consideráveis avanços tecnológicos e do aumento da transparência e participação social nas diferentes esferas e níveis da federação, em maior ou menor grau e, muitas vezes, de forma descontínua e irregular, o Brasil ainda patina na implementação de uma governança pública efetivamente digital, transparente e participativa. Uma série de desafios, limites jurídicos e entraves burocráticos impedem que esse cenário institucional se modifique de forma profunda e duradoura.

Muitas vezes, a manutenção do status quo se dá pelo temor associado à ideia de transformação e inovação, especialmente por aqueles que estão em confortáveis posições de poder e receiam perder seu espaço e privilégios ao compartilhar os processos decisórios. Entretanto, há também hesitações justificáveis de gestores e agentes públicos e elas demandam reflexões ponderadas para se garantir a observância dos princípios democráticos, por exemplo, na prestação remota de serviços públicos e na execução das funções administrativas por meios virtuais.

Resumidamente, os obstáculos hoje no país à consolidação de uma governança digital podem ser classificados em duas naturezas: culturais ou estruturais. De um lado, a cultura institucional, administrativa e política vigente resiste e se opõe à digitalização da Administração Pública. De outro, há dificuldades de ordem técnica e estrutural que freiam esses avanços, tanto aqueles presentes no corpo social (ligados a questões de formação e acesso) como na realidade jurídico-administrativa.

No domínio cultural, podem ser elencadas três espécies de barreiras:

a) A persistência da burocracia como o fator de racionalidade ainda predominante na esfera pública (Saraiva; Capelão, 2000). Isso acarreta uma série de atitudes por parte do corpo administrativo, voltadas à perpetuação dos processos formais existentes, condizentes com a lógica de sistema fechado e inflexível que os rege (Freitas; Darcoso, 2014). Esse apego à burocracia e à forma vazia, sem motivos racionais que as sustentem, atrapalha o progresso tecnológico na seara administrativa e gera perda de eficiência. Todavia, isso não significa que a burocracia deva ser completamente eliminada da administração pública, uma vez que a sua importância reside na institucionalização do controle legalista, do serviço público profissional e de um sistema administrativo impessoal, legal e racional (Bresser-Pereira, 1997). O desafio é evitar o excesso burocrático que embaraça a inovação e uso de 
novas tecnologias sem comprometer o controle estatal e a impessoalidade na administração pública.

b) A existência, até hoje, de traços e valores de administração pública patrimonialista no setor público, que prejudicam as condições básicas de desenvolvimento de uma cultura pública de transparência e accountability (Oliveira; Bodart, 2015). A tradição patrimonialista ainda se expressa, por exemplo, no personalismo presente em alguns setores do funcionalismo público, no uso de cargos e recursos públicos para cooptação de agentes e na busca de realização de interesses pessoais de gestores e políticos, em detrimento do interesse público (Paes, 2005). Esse patrimonialismo é, por sua vez, avesso à transparência, inovação e coparticipação. Assim, apesar de se falar em evolução do modelo patrimonialista para o burocrático e, em sequência, para o gerencial, na verdade, esse processo não é linear e constante. Pelo contrário, subsistem na administração pública brasileira características dos três modelos, ainda que, em tese, já se adote um sistema gerencial.

c) Resistência dos gestores e agentes públicos a se adaptarem às mudanças tecnológicas e aos processos de inovação. Isso porque, além dos motivos já expostos acima, prevalece, ainda, um desinteresse político e ausência de apoio das autoridades em posição de liderança e de priorização da ampliação da transparência pública através de recursos da tecnologia da informação e comunicação (Mezzomo; Wiedenhoft; Santos, 2018).

No que tange às barreiras estruturais, três se relacionam com a ordem administrativa e duas com a sociedade civil:

Dentro da administração pública, percebe-se:

a) Problemas relativos à segurança da informação e da comunicação na esfera pública. A ocorrência de eventos de vazamento de banco de dados sigilosos e de informações públicas sensíveis minam a confiabilidade dos agentes e gestores (além dos cidadãos) no arsenal tecnológico e ferem a garantia de integridade e de autenticidade da informação. Com isso, abre-se brecha para a manipulação de dados e afrontas à confidencialidade de dados pessoais ou à segurança do Estado e da sociedade, bem como cria-se um cenário favorável à propagação de fake news. Esse ambiente institucional promove a desconfiança administrativa e social nas ferramentas de transparência e causam aversão do funcionalismo público na sua utilização, por, muitas vezes, não terem um sistema interno de classificação das informações que funciona adequadamente ${ }^{5}$, o que gera insegurança jurídica e a possibilidade de posterior imputação de responsabilidade.

b) Ausência de corpo administrativo especializado e qualificado e de competências técnicas dentro do quadro de agentes governamentais, além da falta dos investimentos públicos necessários para o uso e avanço das ferramentas tecnológicas e da existência de restrições jurídicas que funcionam

\footnotetext{
${ }^{5}$ No estudo das forças de poder que influenciavam o debate pela aprovação ou não de uma lei de acesso à informação no Brasil, à época da tramitação do PL que resultou na Lei $n^{\circ}$ 12.527/2011, Rodrigues (2020) identifica esse obstáculo no Itamaraty. Justamente por não ter um sistema adequadamente instalado para categorizar os dados que poderiam ser divulgados e os sigilosos, o Itamaraty fazia parte, junto com os militares, de uma coalizão que resistia a uma lei de acesso à informação. Assim, uma barreira estrutural impedia a ampla transparência e retardou por anos a aprovação dessa lei no país; há fortes razões para acreditar que esse obstáculo permanece e resulta em uma resistência à abertura de dados públicos ainda maior.
} 
como entraves à digitalização (Mezzomo; Wiedenhoft; Santos, 2018). Esses fatores ligados à formação, recursos e normatização são essenciais para o pleno desenvolvimento de instrumental da tecnologia da informação e comunicação e expansão do seu uso na administração pública brasileira.

c) Falta de planejamento e coordenação institucionais, de gerenciamento adequado das informações e de integração dos bancos de dados governamentais (Mezzomo; Wiedenhoft; Santos, 2018). Muitas vezes, decisões voltadas à promoção de um governo mais digital são feitas sem o devido planejamento e estabelecimento de metas, etapas e fluxos. Como consequência, nem sempre os resultados esperados são alcançados e as políticas são descontinuadas. Outra questão que permeia a administração pública como um todo é a ausência de uma política coordenada e integrada entre as esferas interorgânicas, intersetoriais e interfederativas para a gestão da informação e dos dados públicos. Isso resulta em duplicidade de esforços para atingir os mesmos objetivos, perdas em eficiência administrativa e desperdício de recursos públicos que, por sua vez, freiam o salto tecnológico na administração pública.

Na sociedade civil, as barreiras estruturais podem ser resumidas em:

a) Ausência de interesse e de confiança dos cidadãos nas instituições, nos dados e nas informações governamentais. O uso dos serviços públicos eletrônicos e as trocas digitais entre sociedade e governo só acontecem se os indivíduos confiam na estrutura tecnológica fornecida e na atuação governamental e se acreditam que suas contribuições causarão impacto (Mezzomo; Wiedenhoft; Santos, 2018).

b) Falta de acesso dos cidadãos aos equipamentos tecnológicos necessários ou falta de capacidade de manejá-los, em razão do fenômeno da exclusão digital e da analfabetização tecnológica (Soares, 2002). A sociedade civil, muitas vezes, tem grandes dificuldades na usabilidade dos instrumentos, na navegabilidade dos portais e na compreensão e assimilação das informações. Isso em razão da complexidade dos sistemas e da linguagem técnica rebuscada e inacessível, que resultam na inteligibilidade jurídica.

Diante de todo o exposto, conclui-se que há ainda muito a avançar na digitalização do governo e que para isso é preciso a superação ou mitigação desses obstáculos culturais e estruturais através de políticas públicas especificamente desenhadas para alcançar tais objetivos. Se, no entanto, não atacarem as verdadeiras causas que barram o progresso tecnológico governamental serão inócuas e inefetivas. Por outro lado, o seu sucesso tem o potencial de gerar ganhos em transparência pública, em participação social nos processos decisórios e em produtividade e eficiência administrativas.

\section{A ATUAL EMERGÊNCIA DE SAÚDE PÚBLICA E CRISE ECONÔMICO-SOCIAL: QUAIS LIÇÕES E OPORTUNIDADES PODEM SER EXTRAÍDAS PARA A EFETIVA IMPLEMENTAÇÃO DA GOVERNANÇA DIGITAL?}

Para se compreender a extensão e profundidade das mudanças e lições a serem extraídas desse novo contexto de imperativa necessidade de utilização dos meios digitais nos processos de formulação de políticas públicas, de execução das funções governamentais, de elaboração de leis e de construção de decisões judiciais, é preciso, antes de mais nada, examinar o arcabouço teórico relativo às contribuições e 
inovações geradas pelo instrumental da tecnologia da informação e comunicação no direito e na democracia.

Na sua aclamada teoria da comunicação de massas, Denis McQuail (2003, p. 4) define como meios de comunicação de massas aqueles "que operam em grande escala, atingindo e envolvendo virtualmente quase todos os membros de uma sociedade em maior ou menor grau", sendo a internet um dos novos meios de comunicação do último século.

Em razão da sua grande relevância social, os meios de comunicação de massa operam consequências para a organização político-jurídica, bem como para a vida sociocultural contemporâneas. No que tange à política e ao direito, as mídias de massas tornaramse gradualmente um componente importante para o processo político democrático, especialmente as digitais. Isso porque elas propiciam uma arena para um debate mais alargado, atuando como um canal de comunicação que flexibiliza as noções de tempo e espaço geográfico e que fornecem um fluxo informativo ininterrupto e instantâneo. Somado a isso, os meios de comunicação digitais podem ser utilizados como ferramentas para expandir a participação popular nas discussões jurídico-normativas (Mcquail, 2003).

Desse modo, a condução da vida política, tanto a nível nacional como internacional, depende cada vez mais dos meios e ferramentas da tecnologia da informação e comunicação. Atualmente, as questões fundamentais para a sociedade quanto à distribuição e exercício de poder ou processos de integração e mudança institucionais se relacionam intimamente com a comunicação digital. Como os meios de comunicação digitais são extremamente eficazes e velozes na formação de opiniões e na influência sobre comportamentos sociais, com especial destaque para esse papel exercido pelas redes sociais, eles constituem uma força potencial para apoiar políticas democráticas e movimentos de reformas sociais (Mcquail, 2003).

Nesse contexto, Hespanha (2009) demonstra que a não correspondência entre os tempos da comunicação jurídica com os da comunicação midiática gera impasses sociais difíceis de serem superados. Na comunicação midiática a informação precisa atuar rápida e continuamente sobre o público e sua sobrevivência depende do seu constante movimento e do fascínio momentâneo que gera nas pessoas. Por sua vez, no direito exige-se a observância de uma sequência de tempos, procedimentos e etapas para a defesa de valores democráticos e republicanos substanciais, processuais e fundamentais, como o contraditório e a publicidade.

Entretanto, isso não significa que a lentidão jurídica seja, em si mesma, intrínseca e invariavelmente benéfica para os processos democráticos. A morosidade excessiva no direito pode se originar de outras causas maléficas e gerar problemas sociais graves, como a inefetividade da decisão administrativa, legislativa ou judicial tomada. Portanto, nem toda lentidão está ligada à satisfação de requisitos essenciais da democracia. Há também leis processuais mal elaboradas, organização institucional deficiente e burocratizada, vícios na formação e cultura dos agentes públicos, magistrados e legisladores que explicam a demora no processo decisório jurídico. Contudo, ainda que todas essas questões fossem superadas e a atuação administrativa, legislativa e judicial fosse a mais eficaz e rápida possível, os ritmos do cotidiano e do direito continuariam consideravelmente diferentes, pois a decisão democrática leva um certo tempo para a maturação, negociação e deliberação (Hespanha, 2009).

Nesse sentido, o impacto atual desses meios de comunicação, particularmente os digitais, pode gerar duas consequências igualmente negativas. De um lado, caso se 
imponha ritmos, fluxos e tempos sociais e midiáticos no direito, que não se compatibilizam com os seus processos, arrisca-se a sua natureza democrática, o rigor jurídico, a justeza e qualidade da decisão tomada. De outro, se o direito não corresponde às expectativas de rapidez e brevidade na apuração dos fatos e tomada da decisão, afasta-se ainda mais dos cidadãos, que percebem suas garantias como excessivas e artificiais e nem sempre conseguem ver valor naquilo que se busca preservar (Hespanha, 2009).

Instaura-se o que Ost (2005) denomina de tirania da urgência e cultura da impaciência. Acostumados com o fluxo midiático instantâneo e constante, os cidadãos desejam que a resposta jurídica seja igualmente ágil e implacável. A preocupação é momentânea e apenas com o agora, sem espaço para refletir sobre potenciais consequências drásticas vindouras. Contra essas abreviações e imposições seria preciso lembrar as virtudes da democracia contínua, que permite o debate e controle sociais. Buscar, portanto, enxergar o valor na cadência ponderada do processo jurídico (quando baseada na dialogicidade) e de reivindicar o direito à lentidão capaz preservar os valores da democracia e justiça. Isso deve, todavia, ser equilibrado com a necessidade de despertar o interesse político do cidadão, evitando que o direito se afaste ainda mais da sociedade (Ost, 2005). A grande dificuldade seria, portanto, conciliar o tempo midiático, e, especialmente, o tempo das mídias digitais e das redes sociais, com os requisitos e exigências do direito e da democracia, sem comprometer o engajamento social na vida política.

Outro grave entrave para a efetivação da aproximação entre a lei e o cidadão é sua dificuldade de acesso e de compreensão do repertório e da linguagem técnico-jurídica. Nesse sentido, a democratização do direito e da política passa pela utilização de estratégias ligadas aos domínios da linguagem e da tecnologia da informação e comunicação. Com esse instrumental, cuja uma das principais características é o traço da virtualidade, é possível consolidar e expandir o acesso à informação jurídica e a participação social na produção do direito (Soares, 2002).

Nesse contexto, Soares (2002) resume algumas das potenciais consequências positivas do impacto tecnológico no direito:

a) Estruturação de banco de dados e de documentação administrativa, jurisprudencial, legislativa e doutrinária mais completos, transparentes e acessíveis;

b) Reconstrução do direito vigente, pois permite a verificação e sistematização normativa diária e feita automaticamente por máquinas, além do controle de revogações;

c) Favorecimento da coerência da ordem jurídica, apesar da inflação legislativa;

d) Melhoria na qualidade e maior democratização da produção legislativa, da formulação de políticas públicas e da construção da decisão judicial;

e) Criação de redes de inovação, informação, articulação e coordenação institucional, incluindo o seu cruzamento entre diversos órgãos da estrutura do Estado.

Com a digitalização do governo, da prestação de serviços públicos e da formulação de políticas públicas, há espaço e potencial para uma maior transparência governamental, previsibilidade das decisões públicas e segurança jurídica, bem como expansão da participação dos cidadãos na administração pública e de controle social das funções administrativas. 
Nesse contexto, recentemente, o mundo inteiro foi abalado com a disseminação de uma nova e grave pandemia que tem gerado impactos profundos e diversos na economia, na organização administrativa e na saúde pública. No que tange à administração pública, tem exigido um repensar sobre o exercício das funções governamentais e prestação dos serviços públicos. Em razão da necessidade de menor contato humano possível para conter a propagação do coronavírus, os novos pilares da atuação administrativa devem ser o trabalho remoto dos funcionários públicos, a virtualização dos serviços e a deliberação digital das decisões públicas. O uso de ferramentas da tecnologia da informação e comunicação pelo governo nunca foi tão imprescindível. Quanto menos depender de espaços físicos e atividades presenciais e quanto mais investir na capacitação digital de seus agentes e na construção de meios virtuais seguros, transparentes e participativos, tanto mais fácil será superar essa emergência de saúde pública.

Trata-se, na verdade, de aproveitar o momento propício atual para dar o salto tecnológico necessário ao direito e à política e promover a democracia e governança pública digitais. Após isso, seria impossível voltar ao estado anterior, pois a crise atuaria como um impulso para a digitalização permanente das atividades estatais, nos âmbitos administrativo, legislativo e jurisprudencial. Nesse contexto:

Esse caminho de digitalização do Estado é sem volta e acompanha a própria tendência da sociedade que se faz cada vez mais social em redes digitais. A transparência, o aumento da participação social e do consumo de serviços digitais públicos são favorecidos por tecnologias da informação e representam uma evolução natural desse processo de digitalização (Freitas; Balaniuk, Silva; Silveira, 2018, p. 132).

Por isso, é preciso se valer dessa situação atípica que exige o exercício do poder de forma remota e digital, para provocar mudanças tecnológicas e institucionais profundas na tomada de decisões públicas. Com isso, seriam criadas novas oportunidades e canais de participação e de incidência política de outros atores sociais, além daqueles que tradicionalmente são ouvidos nesses processos. Nesse sentido, seria uma forma de horizontalizar a decisão pública e ampliar o leque de atores envolvidos, em um ambiente colaborativo virtual. Conforme expõem Mezzomo, Wiednhoft e Santos (2018, p. 283):

[...] as tecnologias participativas e interativas (como ferramentas de mídia social reforçadas por conectividade móvel) ajudam os cidadãos e os governos a aproveitarem e interagirem de forma síncrona uns com os outros para aprimorar a tomada de decisões e permitir o aumento da produtividade (Al-Aufi et al., 2017).

Assim, seria criada a oportunidade digital de a sociedade civil participar como colaboradora durante todo o percurso decisório e não apenas na fase final de avaliação do serviço prestado ou da política já construída. Isso propiciaria, ainda, uma escalada de inovação em rede na elaboração de atos normativos e políticas públicas, na medida em que são feitas a partir de processos colaborativos e ações de inteligência coletiva. É o que Freitas e Dacorso (2014, p. 876) explicam no trecho a seguir: "o sistema de dados abertos apresentado aos clientes/cidadãos se transforma numa plataforma que pode ser escrita, reescrita e modificada por meio de soluções inovadoras". Há, portanto, uma janela de importante oportunidade para um grande salto em tecnologia e inovação na gestão pública brasileira. 


\section{CONCLUSÃO}

É inegável o considerável progresso já alcançado em transparência pública, participação social e governança digital na administração pública brasileira. Houve um significativo aumento do volume de informações públicas disponibilizadas, do controle social e da responsabilização de agentes públicos. Porém, isso ainda tem se dado de maneira muito heterogênea nas diversas esferas de poder e nos diferentes âmbitos federativos; a transparência ativa continua não sendo a regra; frequentemente, as informações são fornecidas em formatos inadequados em padrões não abertos, tornando-as inacessíveis para processamento automático por máquinas; a classificação de documentos como sigilosos ainda é usada de forma excessiva e, quanto à transparência passiva, a qualidade das respostas e a falta de proteção da identidade do solicitante ainda são problemas comuns (Artigo 19, 2017). Por causa desses inúmeros desafios continua sendo oportuna e atual a discussão sobre governo aberto e democracia participativa e digital. As barreiras culturais e estruturais identificadas demonstram a necessidade de implementação e consolidação de um arcabouço de governança no Brasil que proporcione previsibilidade e segurança jurídicas, transforme a abertura de dados e digitalização de serviços públicos em rotina administrativa e viabilize a sustentabilidade e estabilidade dessas iniciativas.

A transparência e a participação não são atributos absolutos, mas sim relativos e, por isso, é possível haver diferentes graus de transparência e de opacidade da informação e de controle e participação cidadãs, conforme a circunstância. Nesse sentido, há um grande potencial disruptivo e inovador no uso de ferramentas de tecnologia da informação e da comunicação para ampliar exponencialmente o grau de transparência, accountability e participação social, construindo uma base sólida na busca pela consolidação de uma governança digital.

Mais do que apenas transportar para o mundo virtual o exercício das funções administrativas já existentes, a digitalização da gestão pública impactará e transformará a forma de atuação governamental, a maneira como os serviços são formulados e prestados e as relações entre o Estado e a sociedade civil. Promoverá, portanto, uma verdadeira revolução e reconstrução da governança brasileira, sob novas bases mais transparentes, participativas e inovadoras. Esse é o caminho para o amadurecimento democrático e desenvolvimento socioeconômico do país e o momento propício para isso é agora.

\section{FINANCIAMENTO}

Coordenação de Aperfeiçoamento de Pessoal de Nível Superior (Capes) - bolsa de doutorado.

\section{REFERÊNCIAS}

ARTIGO 19. Os 5 anos da Lei de Acesso à Informação: uma análise de casos de transparência. Artigo 19, 2017. Disponível em: http://artigo19.org/wpcontent/blogs.dir/24/files/2017/05/Os-5-anos-da-Lei-de-Acesso-à-Informação---umaanálise-de-casos-de-transparência-1.pdf. Acesso em: 06 abr. 2020.

BRASIL. Congresso. Câmara dos Deputados. Projeto de Lei nº 7804/2014. Brasília, 2014. Disponível em: 
https://www.camara.leg.br/proposicoesWeb/fichadetramitacao?idProposicao=620193 . Acesso em: 10 abr. 2020.

BRASIL. [Constituição (1988)]. Constituição da República Federativa do Brasil. Brasília, 1988. Disponível em:

http://www.planalto.gov.br/ccivil_03/constituicao/constituicao.htm. Acesso em: 7 set. 2020.

BRASIL. Controladoria-Geral da União. Guia de implantação de Portal da Transparência. Brasília, 2013. Disponível em: https://www.gov.br/cgu/pt-br/centrais-deconteudo/publicacoes/transparencia-publica/brasiltransparente/arquivos/guia_portaltransparencia.pdf. Acesso em: 18 abr. 2020.

BRASIL. Controladoria-Geral da União. Marcos de governo aberto. Brasília, $2020 b$. Disponível em: https://governoaberto.cgu.gov.br/governo-aberto-no-brasil/marcosde-governo-aberto. Acesso em: 30 mar. 2020.

BRASIL. Controladoria-Geral da União. $1^{\circ}$ Plano de Ação Brasileiro na Parceria para Governo Aberto (OGP). Brasília, 2011. Disponível em: http://www.governoaberto.cgu.gov.br/a-ogp/planos-de-acao/10-plano-de-acao. Acesso em: 28 mar. 2020.

BRASIL. Controladoria-Geral da União. $2^{\circ}$ Plano de Ação Brasileiro na Parceria para Governo Aberto (OGP). Brasília, 2014. Disponível em: http://www.governoaberto.cgu.gov.br/a-ogp/planos-de-acao/2o-plano-de-acaobrasileiro. Acesso em: 28 mar. 2020.

BRASIL. Controladoria-Geral da União. $3^{\circ}$ Plano de Ação Brasileiro na Parceria para Governo Aberto (OGP). Brasília, 2016. Disponível em: http://www.governoaberto.cgu.gov.br/a-ogp/planos-de-acao/3o-plano-de-acaobrasileiro. Acesso em: 28 mar. 2020.

BRASIL. Controladoria-Geral da União. $4^{\circ}$ Plano de Ação Brasileiro na Parceria para Governo Aberto (OGP). Brasília, 2018. Disponível em: http://www.governoaberto.cgu.gov.br/a-ogp/planos-de-acao/40-plano-de-acaobrasileiro. Acesso em: 28 mar. 2020.

BRASIL. Controladoria-Geral da União. Portal da Transparência do Governo Federal. Disponível em: http://www.portaldatransparencia.gov.br. Acesso em: 10 abr. 2020.

BRASIL. Decreto $n^{\circ} 7.724$, de 16 de maio de 2012. Regulamenta a Lei $n^{\circ} 12.527$, de 18 de novembro de 2011, que dispõe sobre o acesso a informações previsto no inciso XXXIII do caput do art. $5^{\circ}$, no inciso II do $\S 3^{\circ}$ do art. 37 e no $\S 2^{\circ}$ do art. 216 da Constituição Federal. Diário Oficial da União, Brasília, 2012. Disponível em: http://www.planalto.gov.br/ccivil_03/_ato2011-2014/2012/decreto/d7724.htm. Acesso em: 7 abr. 2020.

BRASIL. Decreto n 8.638, de 15 de janeiro de 2016. Institui a Política de Governança Digital no âmbito dos órgãos e das entidades da administração pública federal direta, autárquica e fundacional. Diário Oficial da União, Brasília, 2016c. Disponível em: <http://www.planalto.gov.br/ccivil_03/_at02015-2018/2016/decreto/d8638.htm>. Acesso em: 7 set. 2020. 
BRASIL. Decreto $n^{\circ} 8.777$, de 11 de maio de 2016. Institui a Política de Dados Abertos do Poder Executivo federal. Diário Oficial da União, Brasília, 2016a. Disponível em: http://www.planalto.gov.br/ccivil_03/_Ato2015-2018/2016/Decreto/D8777.htm. Acesso em: 20 abr. 2020.

BRASIL. Decreto $n^{\circ} 8.936$, de 19 de dezembro de 2016. Institui a Plataforma de Cidadania Digital e dispõe sobre a oferta dos serviços públicos digitais, no âmbito dos órgãos e das entidades da administração pública federal direta, autárquica e fundacional. Diário Oficial da União, Brasília, 2016b. Disponível em: http://www.planalto.gov.br/ccivil_03/_ato2015-2018/2016/decreto/D8936.htm. Acesso em: 20 abr. 2020.

BRASIL. Decreto $n^{\circ} 9.094$, de 17 de julho de 2017. Regulamenta dispositivos da Lei $n^{\circ}$ 13.460, de 26 de junho de 2017, dispõe sobre a simplificação do atendimento prestado aos usuários dos serviços públicos, institui o Cadastro de Pessoas Físicas - CPF como instrumento suficiente e substitutivo para a apresentação de dados do cidadão no exercício de obrigações e direitos e na obtenção de benefícios, ratifica a dispensa do reconhecimento de firma e da autenticação em documentos produzidos no País e institui a Carta de Serviços ao Usuário (Redação dada pelo Decreto ${ }^{\circ}$ 9.723, de 2019). Diário Oficial da União, Brasília, 2017b. Disponível em:

http://www.planalto.gov.br/ccivil_03/_Ato2015-2018/2017/Decreto/D9094.htm. Acesso em: 30 abr. 2020.

BRASIL. Decreto $n^{\circ}$ 9.319, de 21 de março de 2018. Institui o Sistema Nacional para a Transformação Digital e estabelece a estrutura de governança para a implantação da Estratégia Brasileira para a Transformação Digital. Diário Oficial da União, Brasília, 2018. Disponível em: http://www.planalto.gov.br/ccivil_03/_Ato20152018/2018/Decreto/D9319.htm. Acesso em: 25 abr. 2020.

BRASIL. Decreto n 9.756, de 11 de abril de 2019. Institui o portal único "gov.br" e dispõe sobre as regras de unificação dos canais digitais do governo federal. Diário Oficial da União, Brasília, 2019. Disponível em:

http://www.planalto.gov.br/ccivil_03/_ato2019-2022/2019/decreto/D9756.htm. Acesso em: 23 abr. 2020.

BRASIL. Decreto ${ }^{\circ} 10.332$, de 28 de abril de 2020. Institui a Estratégia de Governo Digital para o período de 2020 a 2022, no âmbito dos órgãos e das entidades da administração pública federal direta, autárquica e fundacional e dá outras providências. Diário Oficial da União, Brasília, 2020a. Disponível em: http://www.planalto.gov.br/ccivil_03/_Ato2019-2022/2020/Decreto/D10332.htm\#art14. Acesso em: 7 set. 2020.

BRASIL. Lei Complementar ${ }^{\circ} 101$, de 4 de maio de 2000. Estabelece normas de finanças públicas voltadas para a responsabilidade na gestão fiscal e dá outras providências. Diário Oficial da União, Brasília, 2000. Disponível em: http://www.planalto.gov.br/ccivil_03/leis/lcp/lcp101.htm. Acesso em: 20 abr. 2020.

BRASIL. Lei $n^{\circ} 12.527$, de 18 de novembro de 2011. Regula o acesso a informações previsto no inciso XXXIII do art. $5^{\circ}$, no inciso II do $\S 3^{\circ}$ do art. 37 e no $\S 2^{\circ}$ do art. 216 da Constituição Federal; altera a Lei no 8.112, de 11 de dezembro de 1990; revoga a Lei no 11.111, de 5 de maio de 2005, e dispositivos da Lei no 8.159, de 8 de janeiro de 1991; e 
dá outras providências. Diário Oficial da União, Brasília, 2011. Disponível em: http://www.planalto.gov.br/ccivil_03/_ato2011-2014/2011/lei//12527.htm. Acesso em: 20 abr. 2020.

BRASIL. Lei no 13.460, de 26 de junho de 2017. Dispõe sobre participação, proteção e defesa dos direitos do usuário dos serviços públicos da administração pública. Diário Oficial da União, Brasília, 2017a. Disponível em:

http://www.planalto.gov.br/ccivil_03/_Ato2015-2018/2017/Lei/L13460.htm. Acesso em: 28 abr. 2020.

BRESSER-PEREIRA, Luiz Carlos. Estratégia e estrutura para um novo Estado. Revista do Serviço Público, v. 48, n. 1, p. 5-25, 1997. Disponível em: https://revista.enap.gov.br/index.php/RSP/article/view/375/381. Acesso em: 12 abr. 2020.

CARVALHO, André; VENTURINI, Otávio. A função do Código de Defesa do Usuário de Serviços Públicos (Lei $n^{\circ}$ 13.460/2017) no modelo brasileiro de controle dos serviços públicos. Revista de Direito Administrativo, Rio de Janeiro, v. 278, n. 1, p. 141-162, jan./abr. 2019.

CRUZ, Flávio da et al. Lei de responsabilidade fiscal comentada: lei complementar $\mathrm{n}^{\circ}$ 101, de 4 de maio de 2000. 2. ed. São Paulo: Atlas, 2001.

FREITAS, José Antônio; BALANIUK, Remis; SILVA, Ana Paula; SILVEIRA, Vitória. O ecossistema de dados abertos do governo federal: um estudo sobre a composição e desafios. Revista Ciência da Informação, v. 47, n. 2, p. 110-132, maio/ago. 2018. Disponível em: http://revista.ibict.br/ciinf/article/view/3952. Acesso em: 10 abr. 2020.

FREITAS, Rony Klay Viana de; DACORSO, Antonio Luiz Rocha. Inovação aberta na gestão pública: análise do plano de ação brasileiro para a Open Government Partnership. Revista de Administração Pública, v. 48, n. 4 p. 869-888, jul./ago. 2014.

HESPANHA, António Manuel. O caleidoscópio do direito: o direito e a justiça nos dias e no mundo de hoje. Coimbra: Almedina, 2007.

MCQUAIL, Dennis. Teoria da comunicação de massas. Lisboa: Fundação Calouste Gulbenkian, 2003.

MELLO, Celso Antônio Bandeira de. Curso de Direito Administrativo. São Paulo: Malheiros, 2013.

MERLO, Sandra; BASSI, Juliane; CRUZ, Jorge. Lei de acesso à informação pública: algumas considerações. Revista do Instituto de Ciências Humanas e da Informação, v. 28, n. 3, p. 73-82, 2014. Disponível em:

https://www.brapci.inf.br/index.php/res/v/23749. Acesso em: 8 abr. 2020.

MEZZOMO, Edimara; WIEDENHOFT, Guilherme; SANTOS, Fábio dos. Barreiras para a ampliação de transparência na administração pública brasileira: questões estruturais e culturais ou falta de estratégia e governança?. Administração Pública e Gestão social, v. 10, n. 4, p. 282-291, out./dez. 2018. Disponível em:

https://periodicos.ufv.br/apgs/article/view/5716. Acesso em: 9 abr. 2020. 
OLIVEIRA, Elisangela Lemos; BODART, Cristiano das Neves. Accountability na administração pública de Vila Velha: uma análise em torno do Orçamento Participativo. In: BODART, Cristiano das Neves (Org.). Gestão pública: transparência, controle e participação social. Vila Velha: Faculdade Novo Milênio, 2015.

OST, François. O tempo do direito. Bauru: Educs, 2005.

PAES, Ana Paula. Por uma nova gestão pública. Rio de Janeiro: FGV, 2005.

PINHO, José Antonio Gomes de; SACRAMENTO, Ana Rita Silva. Accountability: já podemos traduzir para o Português?. Revista de Administração Pública, Rio de Janeiro, v. 43, n. 6, p. 1343-1368, nov. /dez. 2009. Disponível em:

http://www.scielo.br/pdf/rap/v43n6/o6.pdf. Acesso em: 10 abr. 2020.

PLATT NETO, Orion et al. Publicidade e transparência das contas públicas:

obrigatoriedade e abrangência desses princípios na Administração Pública brasileira. Contabilidade Vista \& Revista, v. 18, n. 1, p. 75-94, jan./mar. 2007.

RESENDE, Walisson da Costa; NASSIF, Mônica Erichsen. Aplicação da lei de acesso à informação em portais de transparência governamentais brasileiros. Encontros Bibli, v. 20, n. 42, p. 1-16, jan./abr. 2015. Disponível em:

https://periodicos.ufsc.br/index.php/eb/article/view/1518-2924.2015V2on42p1. Acesso em: 8 abr. 2020.

RODRIGUES, Karina Furtado. A política nas políticas de acesso à informação brasileiras: trajetória e coalizões. Revista de Administração Pública, v. 54, n. 1, p. 142161, jan./fev. 2020. Disponível em:

http://www.scielo.br/scielo.php?script=sci_arttext\&pid=S0034-

76122020000100142\&tlng=pt. Acesso em: 13 abr. 2020.

SARAIVA, Luiz Alex; CAPELÃO, Luiz. A nova administração pública e o foco no cidadão: burocracia × marketing?. Revista de Administração Pública, v. 34, n. 2, p. 5977, mar./abr. 2000. Disponível em:

http://bibliotecadigital.fgv.br/ojs/index.php/rap/article/view/6269. Acesso em: 12 abr. 2020.

SCHAUER, Frederick. Transparencia en tres dimensiones. Revista de Derecho (Valdivia), v. XXVII, n. 1, p. 81-103, jul. 2014. Disponível em:

https://scielo.conicyt.cl/pdf/revider/v27n1/art04.pdf. Acesso em: 2 abr. 2020.

SOARES, Fabiana. Produção do direito e conhecimento da lei a luz da participação popular e sob o impacto da tecnologia da informação. 511f. Tese (Doutorado em Direito)- Universidade Federal de Minas Gerais, 2002.

SOARES, Fabiana; JARDIM, Tarcisio; HERMONT, Thiago. Lei de acesso à informação pública no Brasil: o que você precisa saber. Brasília: Senado Federal, 2013.

TORRES, Marcelo Douglas de F. Estado, democracia e administração pública no Brasil. Rio de Janeiro: FGV, 2004. 